\title{
Selecting and Implementing Resilience Metrics in Existing Energy Sector Models
}

\author{
Caitlin Murphy
}

January 15, 2021

IEEE Task Force on Power System Resilience Metrics and Evaluation Methods 
Resilience Metrics for Informing Decisions Associated with the Planning and Operation of the North American Energy System

Anya Castillo, Robert Jeffers, Katherine Jones, Andrea Staid, and Vanessa Vargas (Sandia National Laboratories)

Bernard Knueven, Sean Ericson, Jessica Lau, and Caitlin Murphy
(National Renewable Energy Laboratory)

Jean-Paul Watson (Lawrence Livermore National Laboratories) Mercy B. DeMenno

NREL is a national laboratory of the U.S. Department of Energy

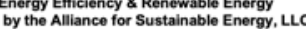

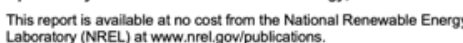
Technical Report
NRELTP-6A20-7420 Contract No. DE-AC $36-086028308$

https://www.nrel.gov/docs/fy20osti/74241.pdf.
Adapting Existing Energy Planning,

Simulation, and Operational Models for Resilience Analysis

Caitlin Murphy, Eliza Hotchkiss, Kate Anderson,

Clayton Barrows, Stuart Cohen, Sourabh Dalvi, Nick Laws, Jeff Maguire, Gord Stephen, and Eric Wilson 


\section{“Defining" Resilience: Mitigating Consequences}

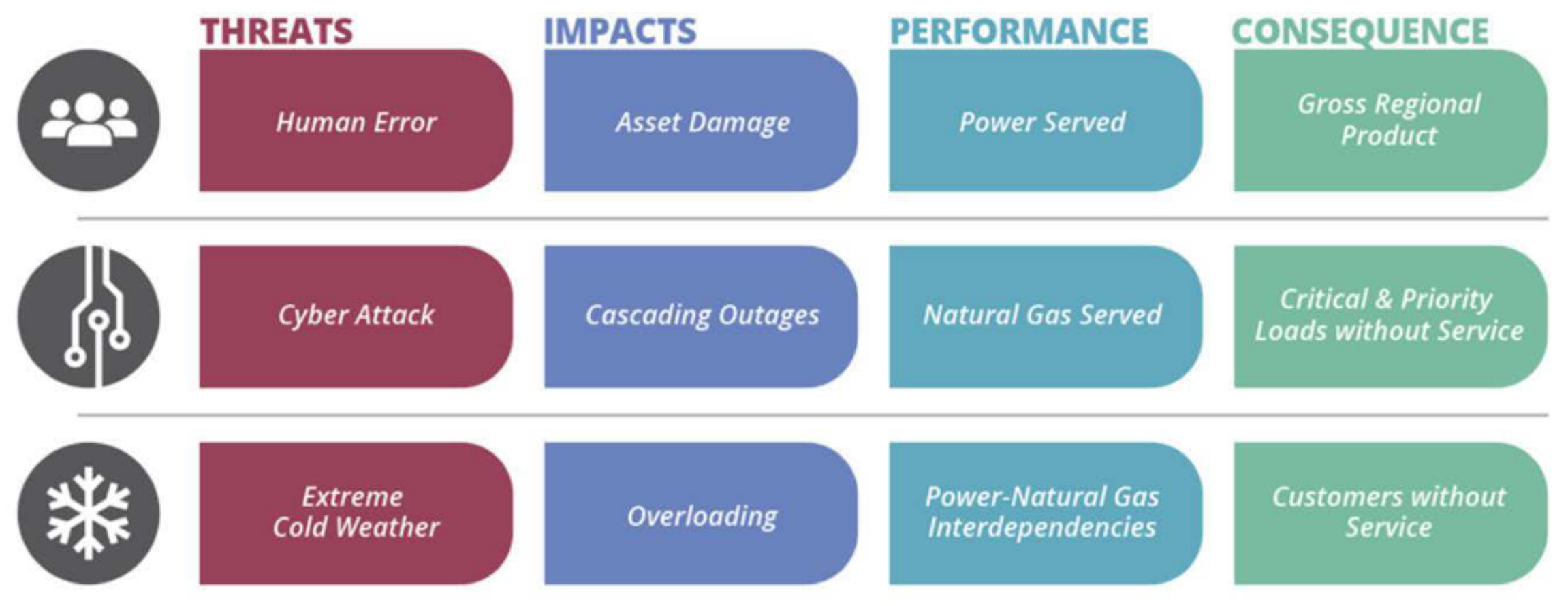

Figure 5. Notional Representation of the Translation of Threats into Consequences 


\section{Modeling Resilience: System Performance}

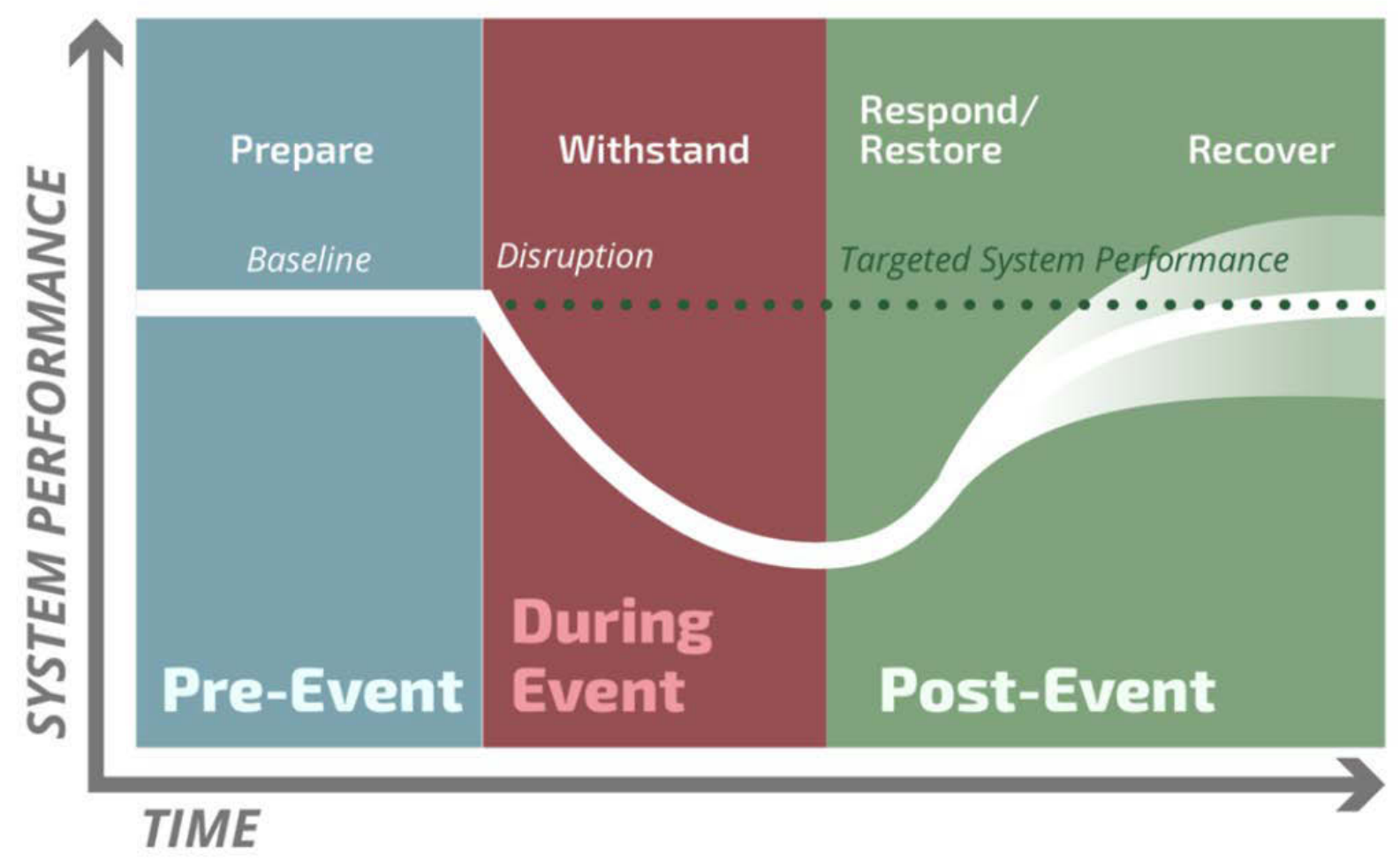

Figure 1. System Performance Curve and Timeline 


\section{Resilience Metrics (or Indicators)}

\section{Energy sector resilience} can be quantified through temporally explicit performancebased metrics or indicators (e.g., comparing baseline and investment scenarios)
Table S.1. Examples of Consequence Categories for Consideration in Grid Resilience Metric Development

\begin{tabular}{ll}
\hline \multicolumn{1}{c}{ Consequence Category } & \multicolumn{1}{c}{ Resilience Metric } \\
\hline Direct & Cumulative customer-hours of outages \\
Electrical Service & Cumulative customer energy demand not served \\
& Average number (or percentage) of customers experiencing an outage during a \\
specified time period & Cumulative critical customer-hours of outages \\
Critical Electrical Service & Critical customer energy demand not served \\
& Average number (or percentage) of critical loads that experience an outage \\
& Time to recovery \\
Restoration & Cost of recovery \\
Monetary & Loss of utility revenue \\
& Cost of grid damages (e.g., repair or replace lines, transformers) \\
& Cost of recovery \\
Avoided outage cost \\
Indirect & Critical services without power (e.g., hospitals, fire stations, police stations) \\
Community Function & Critical services without power for more than $N$ hours (e.g., $N>$ hours of \\
& backup fuel requirement) \\
Loss of assets and perishables \\
Monetary
\end{tabular}




\section{This Study}

- Challenge: Doing resilience analysis "right" requires substantial computational resources and data that are often not available; so what else can you do?

- Interim Solution: modify existing modeling tools to enable imperfect (yet impactful) resilience analyses

- Define power interruption scenarios

- Identify key metrics, based on existing model architecture

- Perform preliminary scenario analysis to demonstrate the ability to inform decisions 


\section{Power Interruption Scenarios}

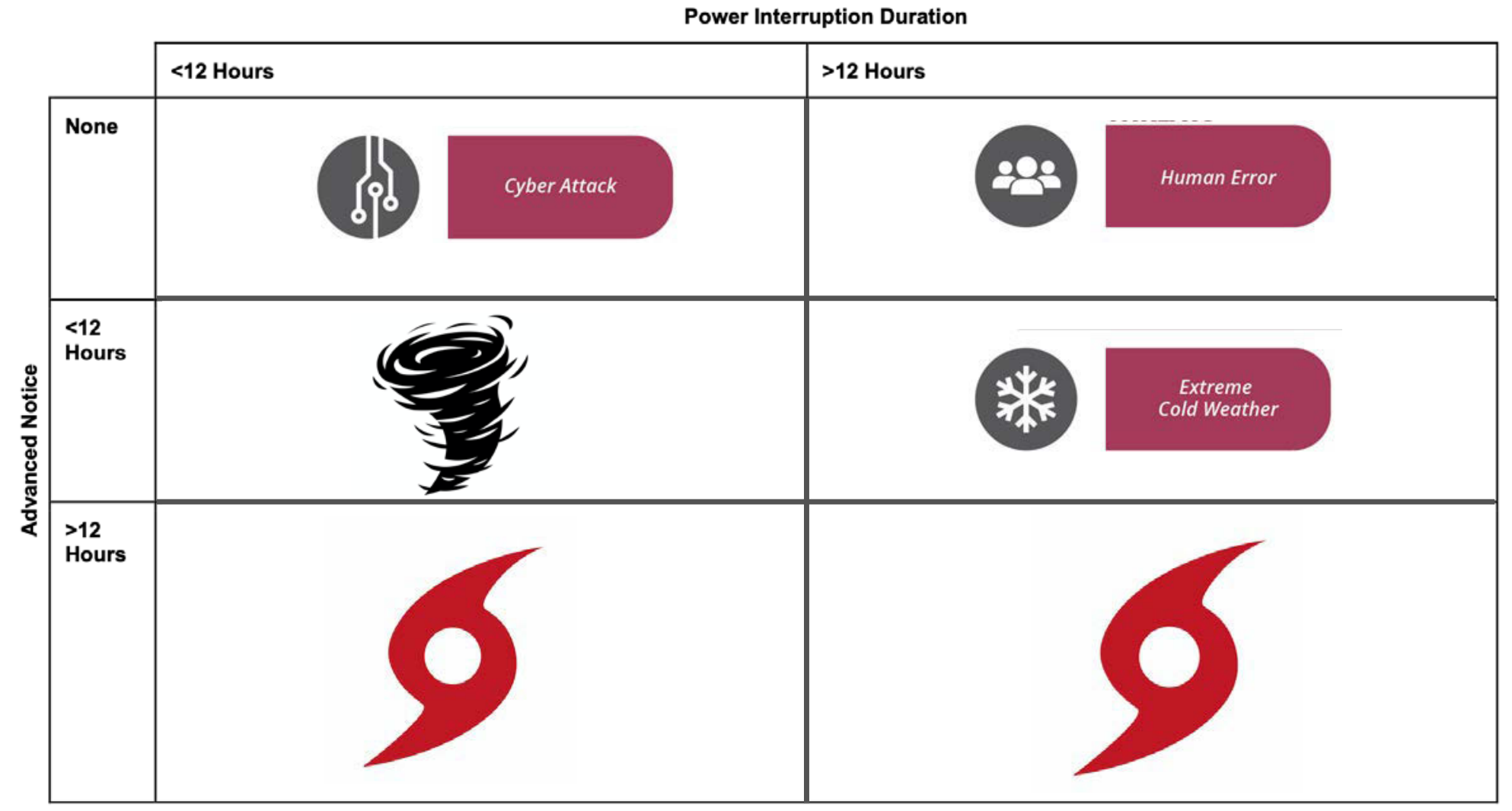




\section{Approach}

Adapt a wide array of energy sector modeling tools to enable (-)ResStock imperfect (yet impactful) resilience analysis, sampling a variety of:

- Energy subsectors

- Geographic scales

- Modeling methods

- Resilience metrics

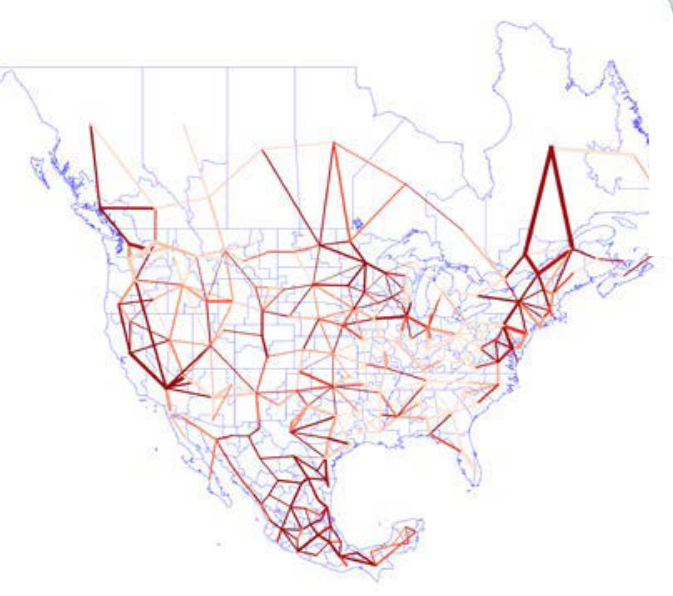

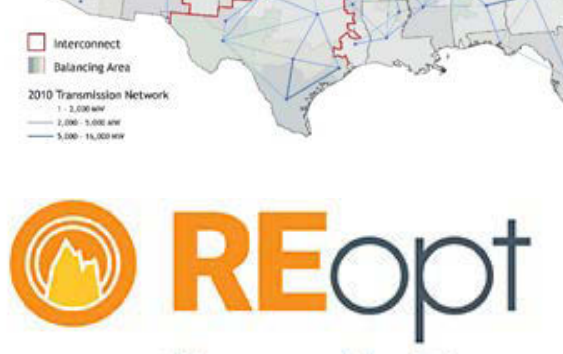

Renewable Energy Integration and Optimization 


\section{Results: ResStock}

Model Description: Physics-based simulation of the energy use and thermal performance of the U.S. residential building stock

Model Update: Development of methods for (1) representing a power outage and (2) measuring thermal resilience

\section{Power Interruption Scenario:}

Long- and short-duration extreme weather with "no notice"

Resilience Metric: time to unsafe indoor conditions

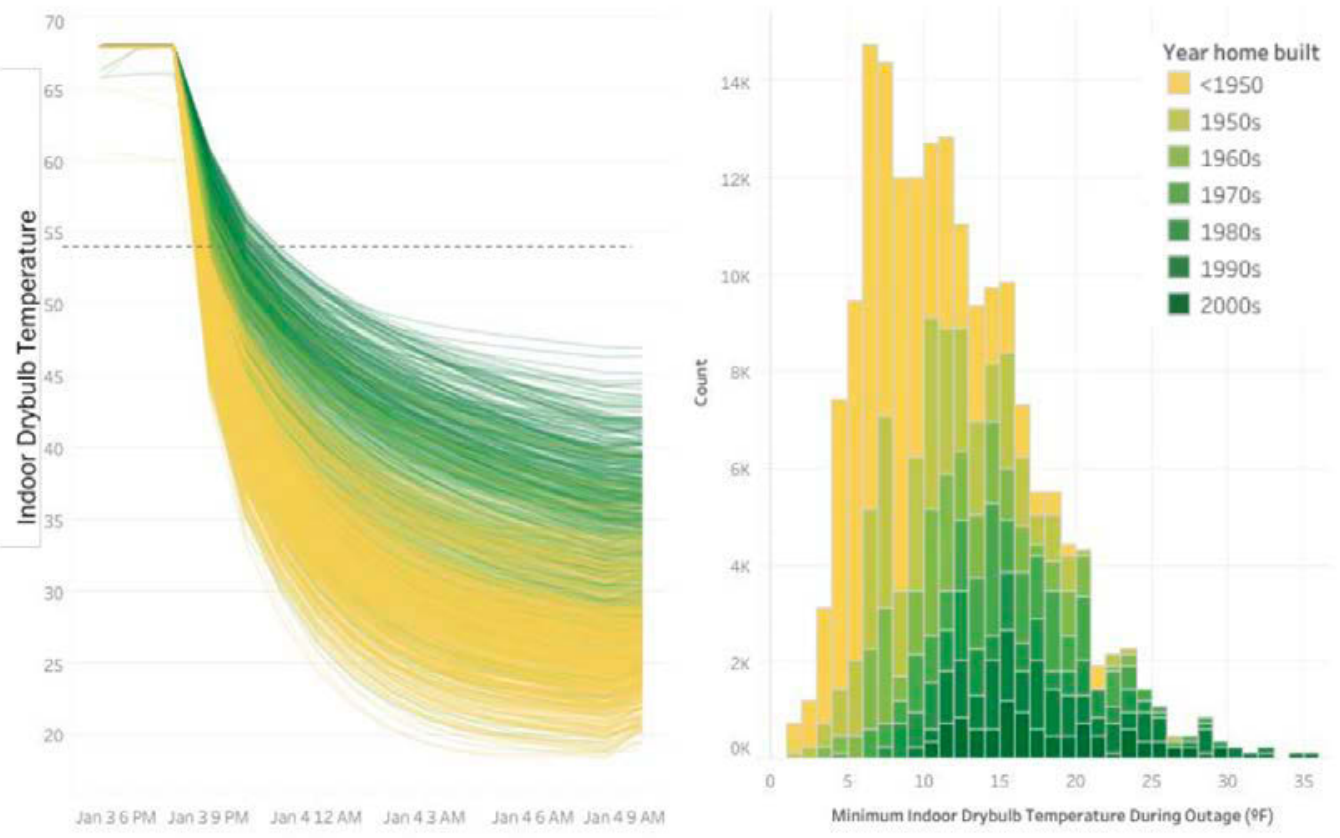

Figure 1. Internal temperature trajectories (left) and distribution of minimum indoor temperatures (right) for buildings in Buffalo, New York, during a power interruption resulting from a hypothetical 12-hour ice storm, as modeled in ResStock

Newer homes, presented in green, typically maintained a livable internal temperature for longer during the hypothetical ice storm, and they maintained higher temperatures overall over the course of the outage. 


\section{Results: REopt}

NREL's Renewable Energy Integration and Optimization Model

- Developed of a methodology for considering avoided power interruption costs in backup power system investments

- Explored a short-duration power disruption with no notice

- Evaluated an avoided outage cost

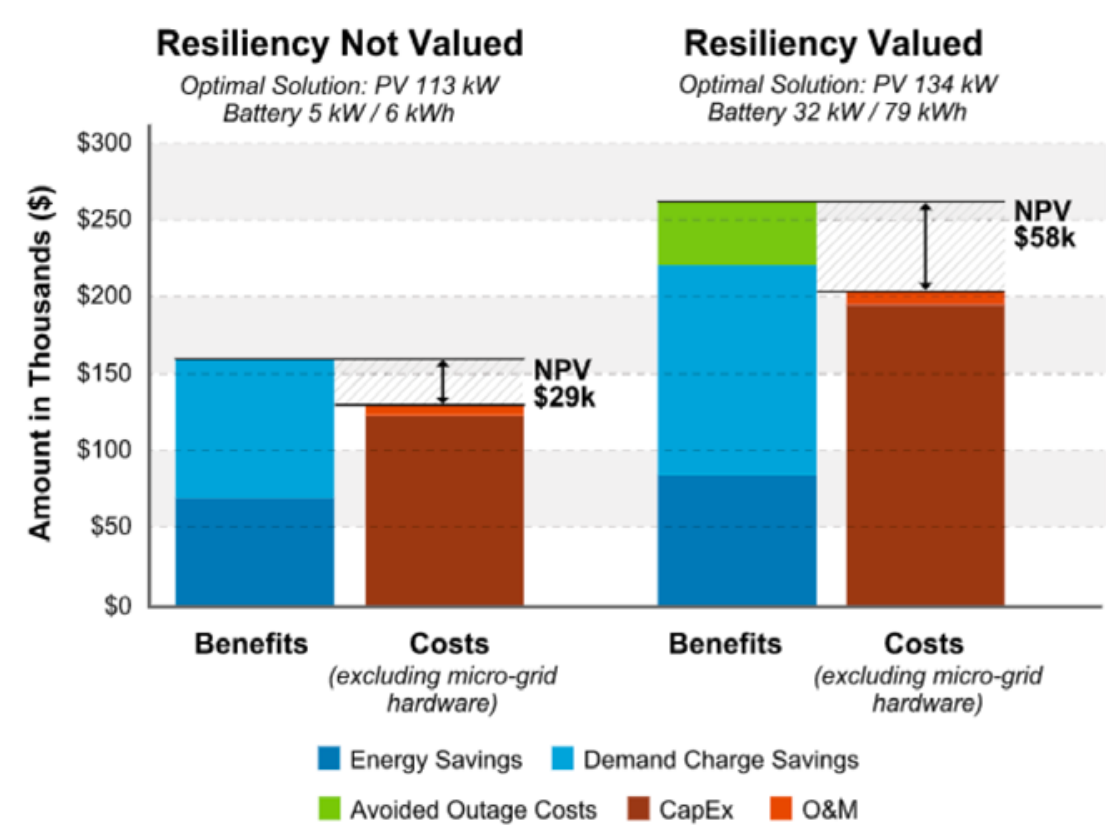

Figure 5. Accounting for the value obtained by mitigating the power interruption experienced by a facility or campus resulted in a cost-optimal backup power system that is larger and incorporates longer-duration storage, as modeled in REopt.

CapEx = capital expenditures, $O \& M=$ operation and maintenance 


\section{Results: PRAS}

\section{NREL's Probabilistic Resource}

Adequacy Suite (PRAS)

- Developed a sequential simulation mode for tracking storage device state-of-charge

- Explored a long-duration fuel supply disruption with no notice

- Evaluated the change in expected unserved energy (EUE) under different

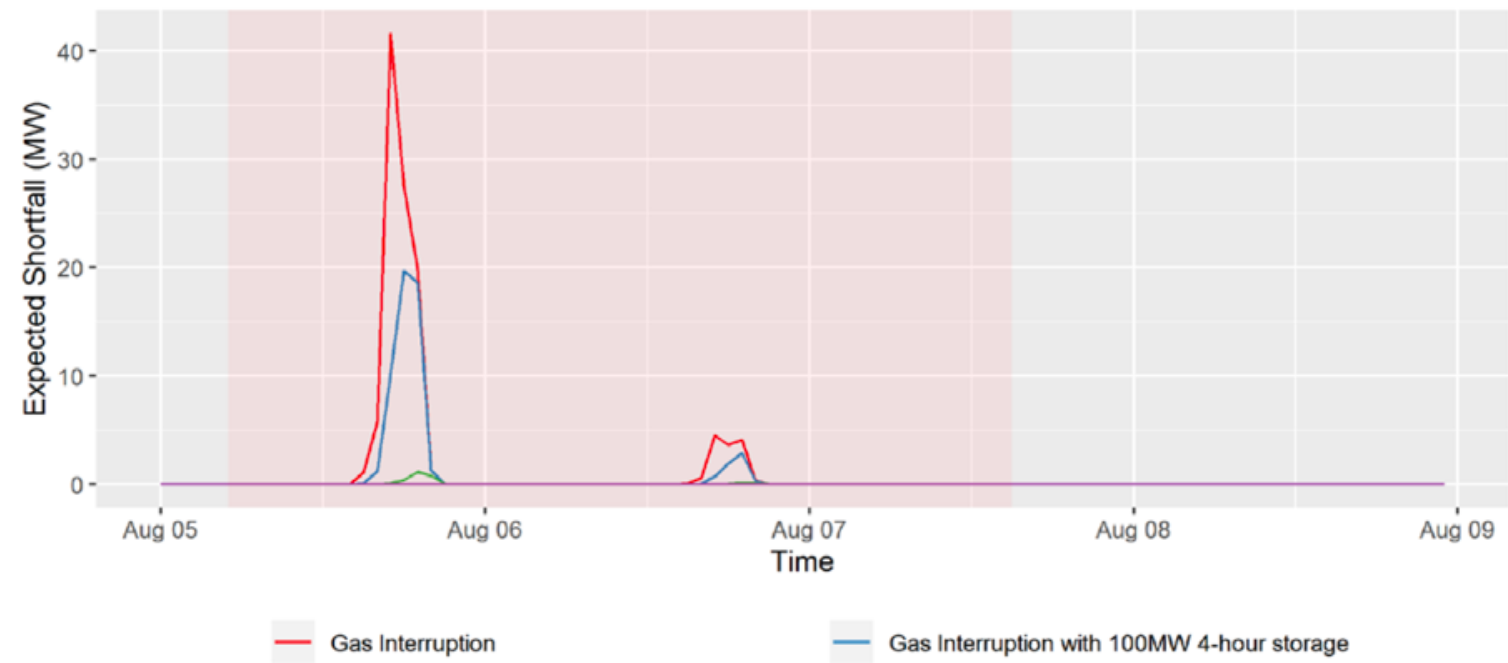

- Gas Interruption with 6x100MW 4-hour storage - No Interruption

Figure 3. Expected unserved energy across natural gas disruption scenarios with varying levels of energy storage capacity, as modeled in PRAS

The four lines demonstrate the expected shortfall (in megawatts) that could occur under scenarios with varying assumptions about natural gas supply interruption and installations of four-hour battery storage systems. Obtaining the total lost load (in megawatt-hours) requires multiplying the expected magnitude and duration of the shortfall. investments scenarios 


\section{Results: SIIP::Power}

NREL's Scalable Integrated Infrastructure Planning (SIIP) Model: Production Cost Model

- Developed a methodology for co-optimizing the dispatch of generation with an outage duration-dependent power interruption cost

- Explored a long-duration power disruption with no notice

- Utilized and evaluated a location- and durationdependent value of lost load (VoLL)
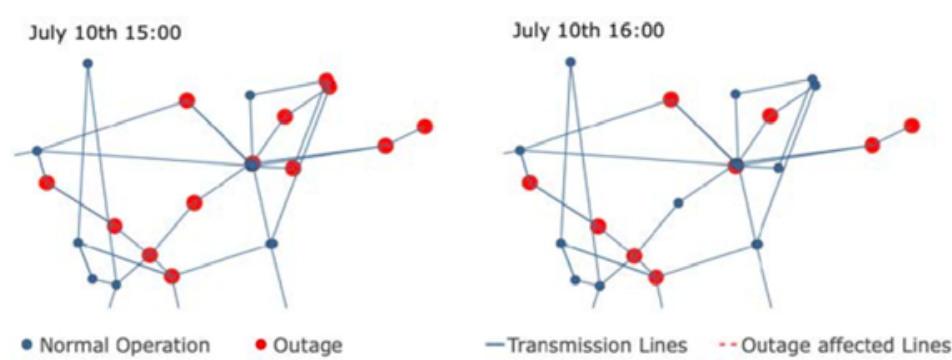

July 10th $15: 00$

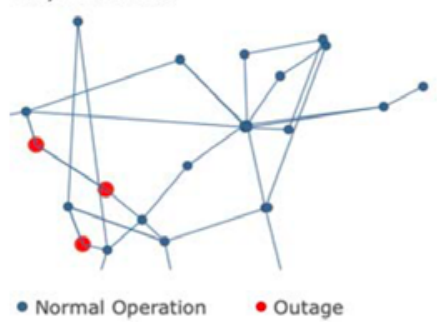

July 10th 16:00

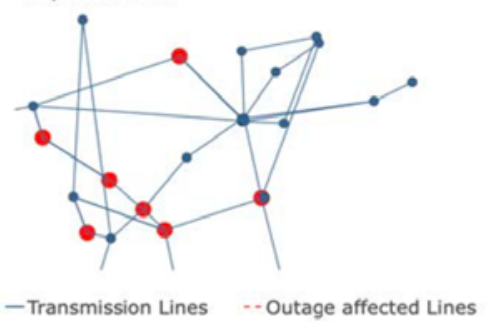

July 10 th $17: 00$

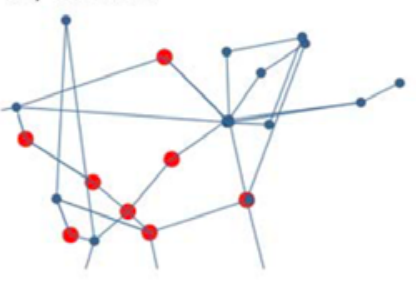

Figure 4. Under degraded conditions, considering a duration-dependent value of lost load resulted in a modified system dispatch, which reduced outage duration at each bus and overall system costs, as modeled in the production cost model framework in SIIP::Power.

Results shown here represent system dispatch in Region 1 of the RTS-GMLC under a power interruption scenario that resulted in a $15 \%$ loss in available generation capacity for 12 hours. The top row shows the dispatch pattern that resulted from consideration of a duration-dependent VoLL, whereas the bottom row considers only a static VoLL.

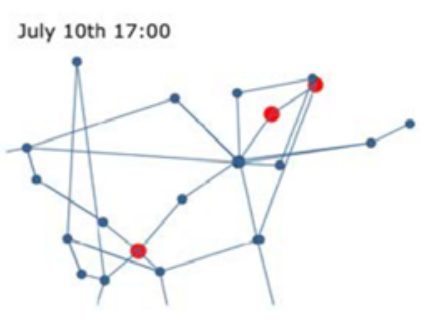




\section{Results: ReEDS}

\section{NREL's Regional Energy}

Deployment System Model

- Increased service

requirements, outage

rates for electricity

generation assets, and

outage rates for

transmission assets

- Evaluated the impacts of redundancy on system performance, makeup, and costs
Table 5. Model Constructs Used to Analyze Resilience Planning in v2018 ReEDS

\begin{tabular}{lll}
\hline $\begin{array}{l}\text { Modification } \\
\text { (Scenario Abbreviation) }\end{array}$ & Intent & $\begin{array}{l}\text { Model Constraints and } \\
\text { Parameter Range }\end{array}$ \\
\hline $\begin{array}{l}\text { Increased operating reserve } \\
\text { requirement }\end{array}$ & $\begin{array}{l}\text { Greater flexibility responding } \\
\text { to short-term outages }\end{array}$ & $\begin{array}{l}3 \%-15 \% \text { of load required as } \\
\text { spinning reserves }\end{array}$ \\
\hline $\begin{array}{l}\text { Increased planning reserve } \\
\text { requirement }\end{array}$ & $\begin{array}{l}\text { Improve resource adequacy } \\
\text { under outages at peak }\end{array}$ & $\begin{array}{l}\text { Regional planning reserve } \\
\text { requirement increased by } 40 \% \mathrm{a}\end{array}$ \\
\hline Higher generator outage rates & $\begin{array}{l}\text { Plan for more frequent } \\
\text { generator outages }\end{array}$ & $\begin{array}{l}\text { Generator forced outage rate } \\
\text { increased by } 50 \% \text { a }\end{array}$ \\
\hline $\begin{array}{l}\text { Higher transmission } \\
\text { outage rate }\end{array}$ & $\begin{array}{l}\text { Plan for more frequent } \\
\text { transmission outages }\end{array}$ & $\begin{array}{l}\text { Transmission forced outage } \\
\text { rate increased up to } 50 \%{ }^{\mathrm{a}}\end{array}$ \\
\hline $\begin{array}{l}\text { Higher transmission outage } \\
\text { rate plus option to purchase } \\
\text { "resilience capacity" }\end{array}$ & $\begin{array}{l}\text { Allow construction of resilient } \\
\text { transmission capacity, e.g., } \\
\text { undergrounding }\end{array}$ & $\begin{array}{l}\text { Transmission forced outage } \\
\text { rate increased up to } 50 \%{ }^{\mathrm{a}}\end{array}$ \\
\hline
\end{tabular}

a Parameter increases or reductions reflect percent changes relative to default assumptions in the 2018 version of the ReEDS model. 


\section{Conclusions}

- Challenge: Doing resilience analysis "right" requires substantial computational resources and data that are often not available

- Interim solution: be creative!

- Long-term solution: develop models that can directly quantify the resilience of energy infrastructure

- Durability/survivability of equipment against threats

- Financial risks associated with investments

- Bulk power system recovery/restoration 


\title{
Thank you! caitlin.murphy@nrel.gov
}

\section{www.nrel.gov}

\author{
NREL/PR-6A20-78943
}

This work was authored in part by the National Renewable Energy Laboratory (NREL), operated by Alliance for Sustainable Energy, LLC, for the U.S. Department of Energy (DOE) under Contract No. DE-AC36-08G028308. This work was supported by the Laboratory Directed Research and Development (LDRD) Program at NREL. The views expressed in the article do not necessarily represent the views of the DOE or the U.S. Government. The U.S. Government retains and the publisher, by accepting the article for publication, acknowledges that the U.S. Government retains a nonexclusive, paid-up, irrevocable, worldwide license to publish or reproduce the published form of this work, or allow others to do so, for U.S. Government purposes. 